\title{
NUEVAS MEDALLAS MAGALLÁNICAS
}

MATEO MARTINIC B."

\section{RESUMEN}

Se da cuenta de ocho medallas magallánicas, dos antiguas y seis recientes, y se hace un comentario sobre las características de las piezas.

PALABRAS CLAVE: medallas, Magallanes.

\section{NEW MAGALLANIC MEDALS}

\section{ABSTRACT}

Eight Magellanic medals are given record of, two old, six recent and some comments are made about the characteristics of the pieces.

KEY WORDS: medals, Magallanes.

Habiendo transcurrido algunos años desde nuestra última comunicación sobre la materia ${ }^{1}$, nos parece conveniente dar cuenta de algunas novedades concernientes a acuñaciones recientes y también a algunas piezas antiguas, a fin de completar el catálogo del conjunto conocido expresivo de la Medallística Magallánica.

1. MEDALLA CONMEMORATIVA DE LA INAUGURACIÓN DEL HORNO DE FUNDICIÓN DEL APOSTADERO NAVAL DE MAGALLANES. Año 1904. Anverso: en el centro el escudo nacional (posiblemente en relieve); leyenda perimetral Apostadero Naval de Magallanes. Reverso: una estrella (posiblemente en relieve). Forma: redonda. Módulo 30mn. Grueso: 10mn. Metal: Bronce.

La información sobre esta rarísima medalla se contiene en el diario El Comercio de Punta Arenas (edición del 20 de junio de 1904), que da cuenta del hecho de haberse fundido únicamente seis ejemplares de la misma pues el molde se rompió.

\footnotetext{
* Profesor Emérito, Centro de Estudios del Hombre Austral. Instituto de la Patagonia, Universidad de Magallanes, Punta Arenas.

${ }^{1}$ Medallas, número VI, Santiago 2001
} 
2. MEDALLA IDENTIFICATORIA DE LA SOCIEDAD EXPLOTADORA DE TIERRA DEL FUEGO. Año, se ignora. Anverso: relieve con la imagen de una oveja (cabeza y parte del cuerpo de semi lado) dentro de un círculo. Leyenda perimetral SOCIEDAD EXPLOTADORA DE TIERRA DEL FUEGO PUNTA ARENAS con un trébol de cuatro hojas a modo de separación. Reverso: liso. Forma: redonda; Módulo: $52 \mathrm{~mm}$. Grueso: $3 \mathrm{~mm}$. Metal: cobre. Depósito: Colección Centro de Estudios del Hombre Austral.

Esta pieza llama la atención por su factura algo burda y porque se desconoce la motivación que pudo darse para su confección. En todo caso es una medalla rarísima (Fig. 1a).

3. CINCUENTENARIO DEL DIARIO "LA PRENSA AUSTRAL". Año 1991. Anverso: en relieve figura en perspectiva que muestra una tira de diario saliendo de la prensa rotatoria en la que alcanza a leerse el titular que expresa Hoy cumplimos medio siglo. En la parte superior la leyenda La Prensa Austral y la portada del edificio del diario. Leyenda semicircular al pie Punta Arenas-Chile. Reverso: liso. Forma: redonda. Módulo: $60 \mathrm{~mm}$. Grueso: 3 mm. Metal: metal doré; Depósito: Colección Centro de Estudios del Hombre Austral (Fig. 1b).

4. SESQUICENTENARIO DE LA CIUDAD DE PUNTA ARENAS. Año 1998. Anverso: en relieve y parcialmente dentro de un recuadro rectangular vertical, la leyenda 150 ANNOS DE LA CIUDAD DE PUNTA ARENAS. Reverso: liso. Forma: redonda. Módulo: $60 \mathrm{~mm}$. Grueso: $3 \mathrm{~mm}$. Metal: metal doré. Depósito: Colección Centro de Estudios del Hombre Austral (Fig. 1c).

\section{RECUERDO DEL MANDO} INSTITUCIONAL DE LA TERCERA ZONA NAVAL. Año 2006. Anverso: en el centro, en relieve, gallardete de mando esmaltado en azul con dos estrellas blancas; en el borde, en doble círculo en relieve la leyenda semiperimetral $C A$. EDMUNDO GONZALEZ ROBLES (parte superior) COMANDANTE EN JEFE III Z.N. (inferior). Reverso: en el centro relieve con el escudo insignia de la Tercera Zona Naval rodeado por un círculo con figura de soga marinera. Forma: redonda. Módulo: $61 \mathrm{~mm}$. Grueso: $5 \mathrm{~mm}$. Metal: bronce mateado.
Depósito: Colección Mateo Martinic B. (Figs. 2a y b). Esta pieza debe ser adscrita a la serie de medallas ocasionales de nuestro catálogo.

\section{CONDECORACIÓN CIUDADANO}

\section{ILUSTRE DE MAGALLANES (Rediseño).}

Año 2008. Esta medalla instituida en 1982 por la Intendencia de Magallanes y Antártica Chilena para premiar el mérito cívico, a partir de 2007 es entregada por el Gobierno Regional de Magallanes y Antártica Chilena, conformado por aquella autoridad y el Consejo Regional. En esta virtud se dispuso el rediseño de la medalla original (descrita bajo el número 70 en Medallas VI), de acuerdo con las siguientes características: conjunto formado por una estrella radial de oro de cinco puntas rematadas en bolas, sobre corona de laureles. En el centro de la estrella una placa esmaltada en colores azul y blanco separados por línea dorada y borde perimetral dorado. En la franja azul corre la leyenda CIUDADANO ILUSTRE DE LA REGIÓN, en letras de oro. El centro de la placa, de color blanco, ostenta el escudo de la Región de Magallanes y Antártica Chilena. Descripción del escudo: división en tres campos, dos verticales y uno basal; campo superior derecho, bandas jaqueladas en color rojo sobre plata, expresivas de las armas del descubridor Fernando de Magallanes; campo superior izquierdo, constelación de la Cruz del Sur en cielo azul; campo inferior, color amarillo ocre con figuración esquemática de matas de pasto coirón expresivo de la riqueza del suelo y subsuelo de la estepa magallánica. Bajo el escudo, cartela con el lema PRIMA IN TERRA CHILENSIS, significativa de la primacía geográfica e histórica de la Región de Magallanes. Con argolla. Módulo 50 mm. Metal: metal doré.

\section{CINCUENTENARIO DE LA CREACIÓN} DEL PARQUE NACIONAL TORRES DEL PAINE. Año 2009. Anverso: en el centro relieve con la silueta de las Torres del Paine y dos cóndores, con la leyenda 50 AÑOS, conjunto rodeado por línea semicircular en relieve y la fecha 1959-2009; leyenda perimetral PARQUE NACIONAL TORRES DEL PAINE El Paraíso de la Patagonia. Reverso: en el centro relieve con el logo del Gobierno de Chile y la frase GOBIERNO DE CHILE MINISTERIO DE AGRICULTURA CONAF, conjunto circundado en relieve por la leyenda perimetral CORPORACIÓN 


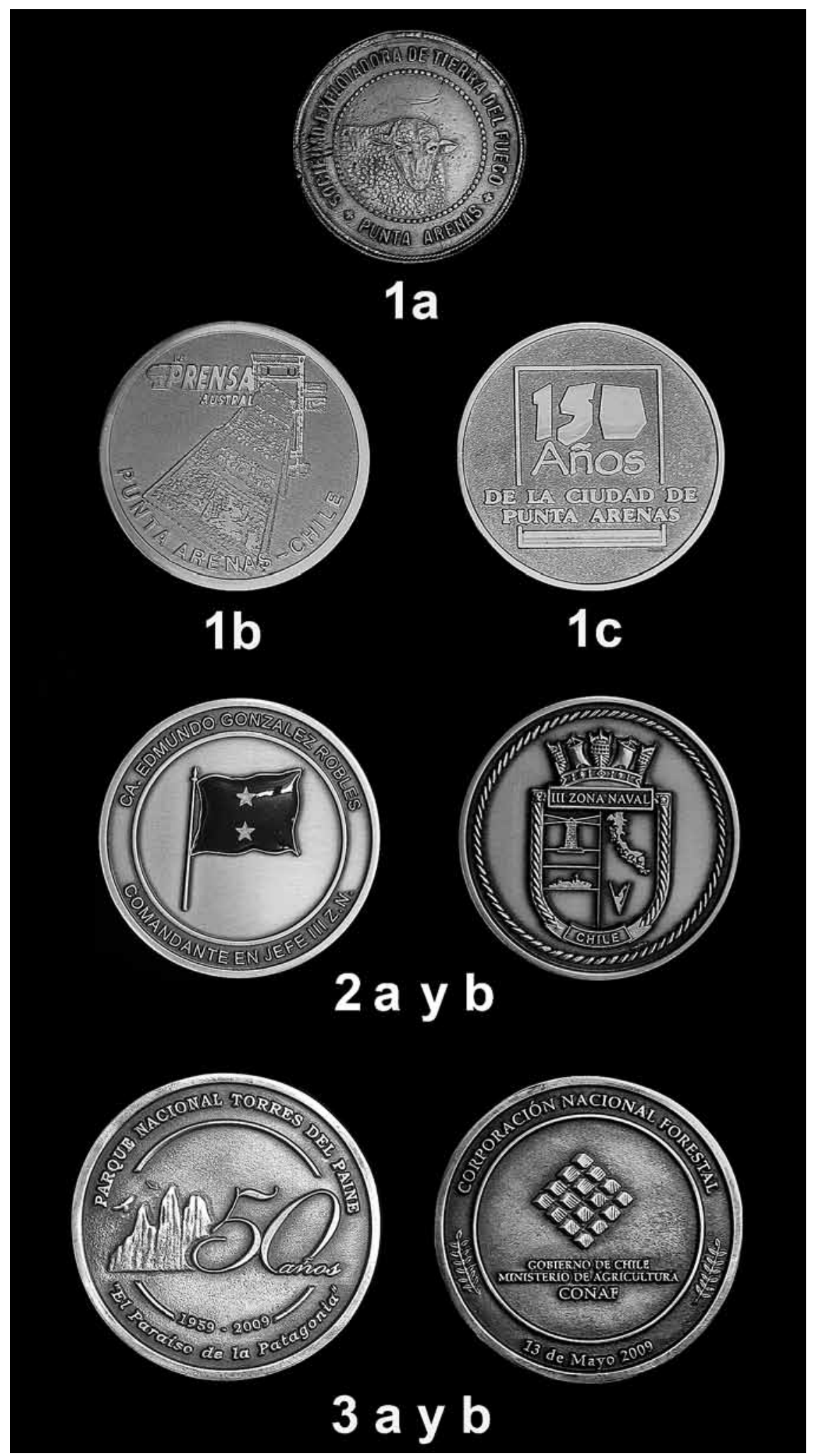


NACIONAL FORESTAL, con ramas de trece hojas y al pie la fecha 13 de mayo de 2009. Forma: redonda. Módulo: $68 \mathrm{~mm}$. Grueso: $4 \mathrm{~mm}$. Metal: metal blanco. Depósito: Colección Mateo Martinic (Figs. 3a y b).

Esta medalla, como la descrita en el número 2 corresponde a la serie conmemorativa del catálogo mencionado.

8. Queda todavía una medalla curiosa, cuyo anverso muestra en relieve la efigie de Hernando de Magallanes idéntica a la descrita entre las medallas conmemorativas de nuestro catálogo (I-a.2) y la fecha 1920. El reverso sólo muestra la letra $R$ con un punto sobre la "pata" derecha. Es de forma redonda y bordes irregulares, con un diámetro de $23 \mathrm{~mm}$ y $2 \mathrm{~mm}$ de grueso, y está confeccionada en plomo. Esta última característica nos sugiere el uso de la pieza como sello para fines indeterminados. Para su confección parece haberse usado como molde el huecograbado de la medalla conmemorativa del Cuarto Centenario del Descubrimiento del estrecho de Magallanes citada precedentemente.

Por fin, cabe un comentario referido a una de las medallas agregadas por la Dirección de la revista Medallas al catálogo de 2001, al tiempo de diagramarse el artículo correspondiente ( $\mathrm{N}^{\circ} 83$ ), en cuanto a su condición de ser pieza magallánica, lo que no corresponde puesto que en realidad se trata de una medalla acuñada por la Sociedad Anónima Ganadera Menéndez Behety (Argentina) para premiar a sus colaboradores en ese país. La misma nos era conocida y obra en la Colección del Centro de Estudios del Hombre Austral.

Con lo expuesto en esta nota reafirmamos la certidumbre que tenemos en cuanto a que Magallanes es la región de Chile que cuenta con mayor cantidad de medallas.

\section{BIBLIOGRAFÍA}

Martinic, M. (1976). Medallas de Magallanes. Anales del Instituto de la Patagonia, 7, 43-57.

Martinic, M. (1997). Medallas de Magallanes II. Anales del Instituto de la Patagonia, 25, 27-33.

Martinic, M. (2001). Medallas Magallánicos. Medallas. 6, 15-30. 